\title{
Quality appraisal of Mango flavored milk prepared from different combinations of Nili Ravi buffalo and Holstein Friesian cow milk
}

Saima Inayat ${ }^{1 *}$, Asma Nazir ${ }^{2}$, Muhammad Tarique Tunio ${ }^{2}$ and Mushtaq Hussain Lashari ${ }^{3}$

1. Department of Dairy Technology, University of Veterinary and Animal Sciences, Lahore-Pakistan

2. Livestock Management, Faculty of Sciences, Allama Iqbal Open University, Islamabad-Pakistan

3. Department of Life Sciences, The Islamia University of Bahawalpur, Bahawalpur-Pakistan

*Corresponding author's email: saima.inayat@uvas.edu.pk

Citation

Saima Inayat, Asma Nazir, Muhammad Tarique Tunio and Mushtaq Hussain Lashari. Quality appraisal of Mango flavored milk prepared from different combinations of Nili Ravi buffalo and Holstein Friesian cow milk. Pure and Applied Biology. Vol. 10, Issue 1, pp69-80. http://dx.doi.org/10.19045/bspab.2021.100011

Received: $22 / 06 / 2020$

Revised: 24/08/2020

Accepted: $31 / 08 / 2020$

Online First: 14/09/2020

\section{Abstract}

Present study was carried out to assess the compositional quality of mango flavored milk produced from Nili Ravi buffalo (100\%), Holstein Friesian cow milk (100\%); the best milk breeds globally recognized and their blends in 75\%:25\%, 50\%:50\% and 25\%:75\% respectively. Another aim was to evaluate which of buffalo and cow milk or their blends will best meet consumers demand in terms of their compositional quality and taste. Shelf life was also considered for all the flavored milks. Trained judges were asked to evaluate each of the five groups of flavored milk samples and provided feedback about their sensory assessment. Comparative analysis was undertaken using one-way ANOVA at SPSS 17 for significant difference comparison, while cross tabs and chi-square tests were used for the distribution and significance of response of the consumers for the taste of milk. Results indicated that five groups of flavored milks differed significantly among each other $(\mathrm{p}<0.05)$. The difference among the groups was also statistically significant for all the parameters except lactose $(p=0.341)$. Shelf life of all the samples showed reasonably good results till 7 days of storage at refrigerated temperature of $4^{\circ} \mathrm{C}$. As per majority of the respondents, flavored milk prepared from buffalo milk (T0) remained the best among all five groups of flavored milks with respect to all tested quality parameters as Pakistani consumers always prefer buffalo milk over cow milk for its overall acceptability of taste, odor and colour.

Key words: Flavored milk; Holstein Friesian cow milk; Mango flavor; Nili Ravi buffalo milk; Sensory analysis

\section{Introduction}

Milk is the economical source of all nutrients when compared with other food items. It is a secretion of mammary gland, and is the only food for young mammals during the first period of life, as it provides 
both energy and body building materials necessary for growth besides immunity to young mammals through its antibodies [1]. Livestock is a backbone of country's economy and Pakistan is blessed with a large population of cattle and buffaloes. Pakistan is ranked $4^{\text {th }}$ among the top milk producing countries of the world, producing about 59,759 thousand tons of milk [2].

In Pakistan, buffalo milk is used in the manufacture of traditional as well as industrial dairy products due to its healthy nutritive properties [3]. Buffalo milk contains total solids and fat contents higher than cow milk that makes it richer, creamier and thicker. Buffalo milk also contains more calcium, better calcium to phosphorus ratio and lesser in sodium and potassium, and is a better nutritional supplement for infants. Buffalo milk is really beneficial for bones, teeth and nutrition. Solids not fat (SNF) contents to reducing sugar contents in milk samples from various cow and buffalo species were compared [4] and concluded that both SNF and fat contents were comparatively higher in all the buffalo milk samples.

Buffalo milk is commercially more viable than cow milk for the manufacture of fat and SNF milk based products such as butter, ghee, ice cream, cheese, milk powder because of its lower water contents and higher fat. The higher level of fats and proteins of buffalo milk also makes it more economical alternative to cow milk for the production of casein, caseinates, whey protein concentrates and a wide range of the fat rich dairy products [3]. Ash, total solids, lactose, protein and fat contents of 40 samples each of cow and buffalo milk were compared [5] and concluded a statistically significant difference between the two sources of milk. Buffalo milk was found valuable for dairy products as a fat rich base as well as for nutritious soft drinks because of its richness in micro-nutrients and lesser ash contents, while cow milk is good for use as low fat base of dietary products and drinks. [6] studied chemical composition of buffalo and cow milk as well as the dairy products obtained from their milk. Buffalo milk had higher level of fat (4.9 percent), total protein (3.6 percent), total solids (13.4 percent) and ash (0.76 percent) than cow milk (3.2, 3.2, 12.1, and 0.65 percent respectively). The gross composition was found at the higher levels in cream, butter ghee and yoghurt from buffalo milk as compared with cow milk.

Flavored milk is more nourishing alternative to plain milk, and assists in improving the dairy utilization by children [7]. Survey among 8-13 year old children by [8] showed children purchased more milk when the milk offerings have been improved with flavored milks. A variety of flavored products have been developed in Pakistan. Several conventional methods, like Rabbri doodh, badam doodh, doodh soda, bottle doodh etc are practiced commercially since long in Pakistan to improve the flavour and acceptability of milk. But they are generally perceived insufficient in meeting the dietary requirements of children in the growing age. Keeping in view the above facts following study has been designed. The Nili Ravi buffalo breed and Holstein Friesian cow breeds are considered as the world best renowned milch breeds throughout the globe. The composition and nutrition of both breeds have unique characteristics in their own. The current research is intended to study nutritional composition, sensory evaluation and shelf life study of mango flavoured milk produced from Nili Ravi buffalo and Holstein Friesian milk with their blends.

\section{Materials and Methods Collection of milk samples}

The fresh raw milk of Nili Ravi buffalo and Holstein Friesian cows procured from BBlock, Ravi campus, UVAS, Pattoki. The 
milk collected in the batches of 13 liters and it has been standardized, pasteurized and processed. The required chemicals purchased from local market, Lahore. The collected samples have been dispatched to the laboratory of Dairy Technology and were stored at $4^{\circ} \mathrm{C}$ temperature till analyses and further processing.

\section{Preparation of flavored milk}

Milk has been pasteurized up to $72^{\circ} \mathrm{C}$ for 05 minutes and during attaining temperature $72^{\circ} \mathrm{C}$ a mix of Recodon (0.5 gm/lit) $(6.5 \mathrm{gm})$ + Cremodon $(0.5 \mathrm{gm} / \mathrm{lit})(6.5 \mathrm{gm})+$ Color $(2$ gm) + Sugar $(650 \mathrm{gm})$ has been added and then 2 minutes before the milk cooled to $4^{\circ} \mathrm{C}$, flavor $(0.9 \mathrm{ml} / \mathrm{lit})(12 \mathrm{ml})$ has been added to it. Then the milk has been packaged in $250 \mathrm{ml}$ polyethylene PET bottles and has been stored at $4^{\circ} \mathrm{C}$ for further chemical analysis.

Flavoured milk has been manufactured in the Postgraduate Laboratory, Department of Dairy Technology, UVAS, Ravi campus Pattoki. Buffalo milk (Nili Ravi) has been kept as control and blended it with cow milk in different proportions as mentioned in (Table 1) for present study. As T0 (5L) buffalo milk; T1 (3.75L) buffalo milk and (1.25L) cow milk; T2 (2.5L) buffalo milk and $(2.5 \mathrm{~L})$ cow milk; T3 $(1.25 \mathrm{~L})$ buffalo milk and (3.75L) cow milk; T4 (5L) cow milk were used.

Table 1. Groups of flavored milk based on cow and buffalo milk blends

\begin{tabular}{|c|c|c|}
\hline Treatments & Buffalo milk (Nili Ravi) & Cow milk (Holstein Friesian) \\
\hline $\mathbf{T}_{\mathbf{0}}$ & $100 \%$ & - \\
\hline $\mathbf{T}_{\mathbf{1}}$ & $75 \%$ & $25 \%$ \\
\hline $\mathbf{T}_{\mathbf{2}}$ & $50 \%$ & $50 \%$ \\
\hline $\mathbf{T}_{\mathbf{3}}$ & $25 \%$ & $75 \%$ \\
\hline $\mathbf{T}_{\mathbf{4}}$ & - & $100 \%$ \\
\hline
\end{tabular}

Quality assessment of the flavored milk Physical and Chemical ( $\mathrm{pH}$, titrable acidity, specific gravity, proteins, fats, total solids, solids-not-fats, lactose and Ash) contents were determined according to the standard methods as prescribed by Association of Official and Analytical Chemists [9-12]. Milk appearance used as the shelf study indicator when it was stored in a refrigerator at $4^{\circ} \mathrm{C}$. Sensory evaluation was carried out by questionnaire survey among judges.

\section{Statistical analysis}

Comparative analyses was undertaken using one-way ANOVA at SPSS 17 to see if the milk groups significantly differed in their properties, while cross tabs and chi-square was used for the distribution and significance of response of the consumers for the taste of the flavored milks.

\section{Results}

The findings for all common milk quality parameters (total solids, protein, fat, solids not fat (SNF) contents, lactose, ash, titratable acidity as well as $\mathrm{pH}$ and specific gravity of the five groups of flavored milks developed from Nili Ravi buffalo and Holstein Friesian cow milk. By mixing in 75 and $25 \%, 50$ and $50 \%$, and 25 and $75 \%$, respectively, both in tabular and graphical illustrations, besides the statistical significance of the difference in the means of these parameters among five groups of the flavored milk were determined. The values of their descriptive (mean, standard deviation, standard error, minimum and maximum, the confidence intervals) for each, assessed by running one-way ANOVA on SPSS 17. Appearance, taste, colour, flavour and overall acceptability of all groups of flavored milks were inquired by a panel of trained judges using nine point hedonic scale criteria. Cross tabulation with chi-square test run on Minitab 17 was used to compare the response of the respondents 
regarding milk sensory attributes. Results of shelf life study were also investigated.

\section{Titrable acidity \%}

The graphical presentation (Fig. 1) presents comparison of the titrable acidity (means for the three trials) among the five groups of the flavored milk. From the vertical heights of the bars and the values shown at the outside edges of the bars, it is clear that flavored milk from solely buffalo milk exhibited the highest titrable acidity; while milk produced solely from cow milk has the lowest titrable acidity. This difference was also highly significant statistically $(\mathrm{p}<0.05)$ at $95 \%$ level of significance.

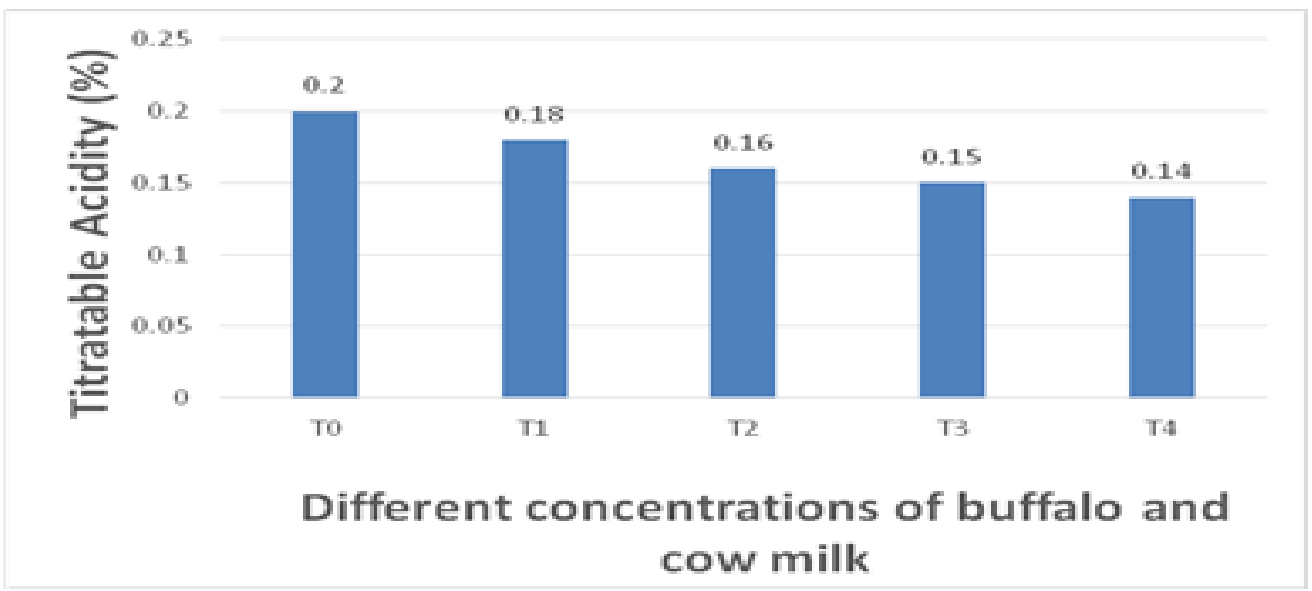

Whereas $\mathrm{T}_{0}=100 \%$ buffalo milk $+0 \%$ cow milk, $\mathrm{T} 1=75 \%$ buffalo milk $+25 \%$ cow milk blend, $\mathrm{T} 2=$ $50 \%$ buffalo milk $+50 \%$ cow milk blend, $\mathrm{T} 3=25 \%$ buffalo milk $+75 \%$ cow milk blend, $\mathrm{T} 4=0 \%$ buffalo milk $+100 \%$ cow milk blend

Figure 1. Mean values of titrable acidity in the five groups of flavored milk

pH

Contrary to the trend observed for titrable acidity, $\mathrm{pH}$ was maximum in flavored milk that was based solely on cow milk, and minimum in the flavored milk based solely on the buffalo milk, as can be observed from the values written at the top of the bars, and the heights of the bars, in the bar chart (Fig. 2).

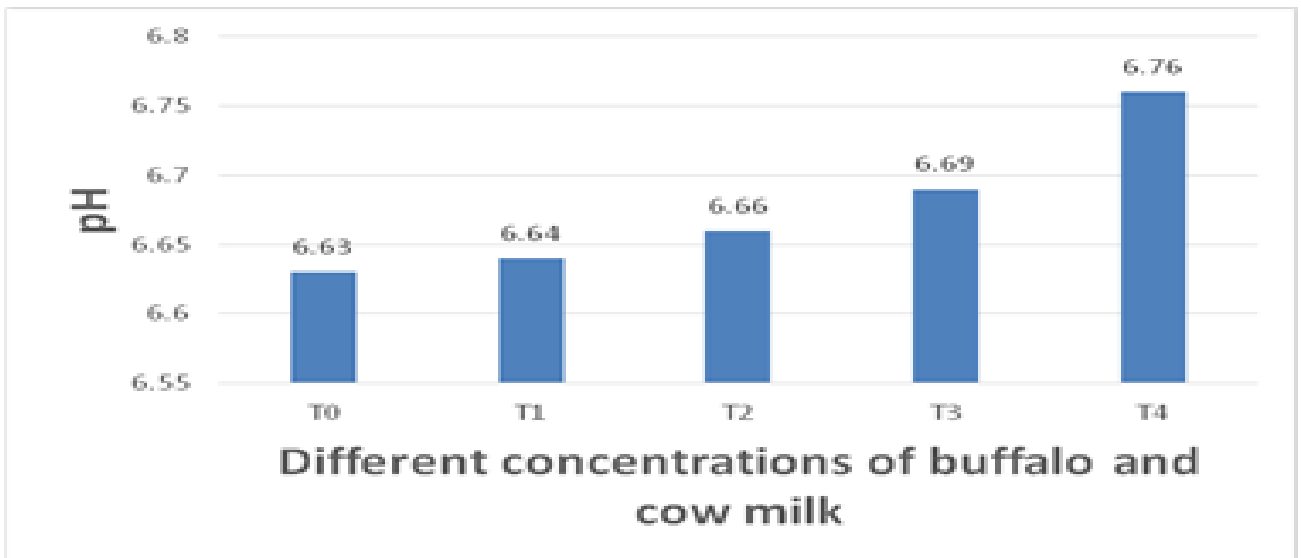

Whereas $\mathrm{T}_{0}=100 \%$ buffalo milk $+0 \%$ cow milk, $\mathrm{T} 1=75 \%$ buffalo milk $+25 \%$ cow milk blend, $\mathrm{T} 2=50 \%$ buffalo milk $+50 \%$ cow milk blend, $\mathrm{T} 3=25 \%$ buffalo milk $+75 \%$ cow milk blend, $\mathrm{T} 4=0 \%$ buffalo milk $+100 \%$ cow milk blend

Figure 2. Mean values of $\mathrm{pH}$ in the five groups of flavored milk 


\section{Specific gravity}

Only buffalo milk flavored milk had higher specific gravity on average as compared to all other groups of flavored milk, as it is obvious from the bar chart in (Fig. 3).

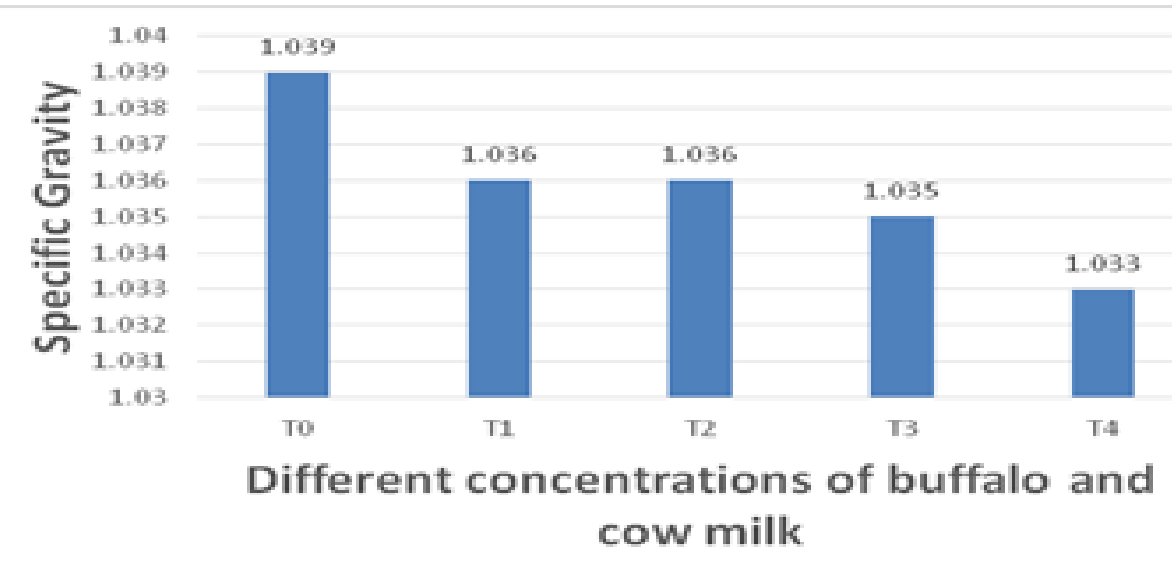

Whereas $\mathrm{T}_{0}=100 \%$ buffalo milk $+0 \%$ cow milk, $\mathrm{T} 1=75 \%$ buffalo milk $+25 \%$ cow milk blend, $\mathrm{T} 2=50 \%$ buffalo milk $+50 \%$ cow milk blend, $\mathrm{T} 3=25 \%$ buffalo milk $+75 \%$ cow milk blend, $\mathrm{T} 4=0 \%$ buffalo milk $+100 \%$ cow milk blend

Figure 3. Mean values of specific gravity in the five groups of flavored milk

\section{Total solids\%}

Buffalo milk based flavored milks had higher values of average total solids contents (Fig. 4) than all other groups of flavored milks, as can be noted from the bar chart and the values on the charts or the heights of the bars.

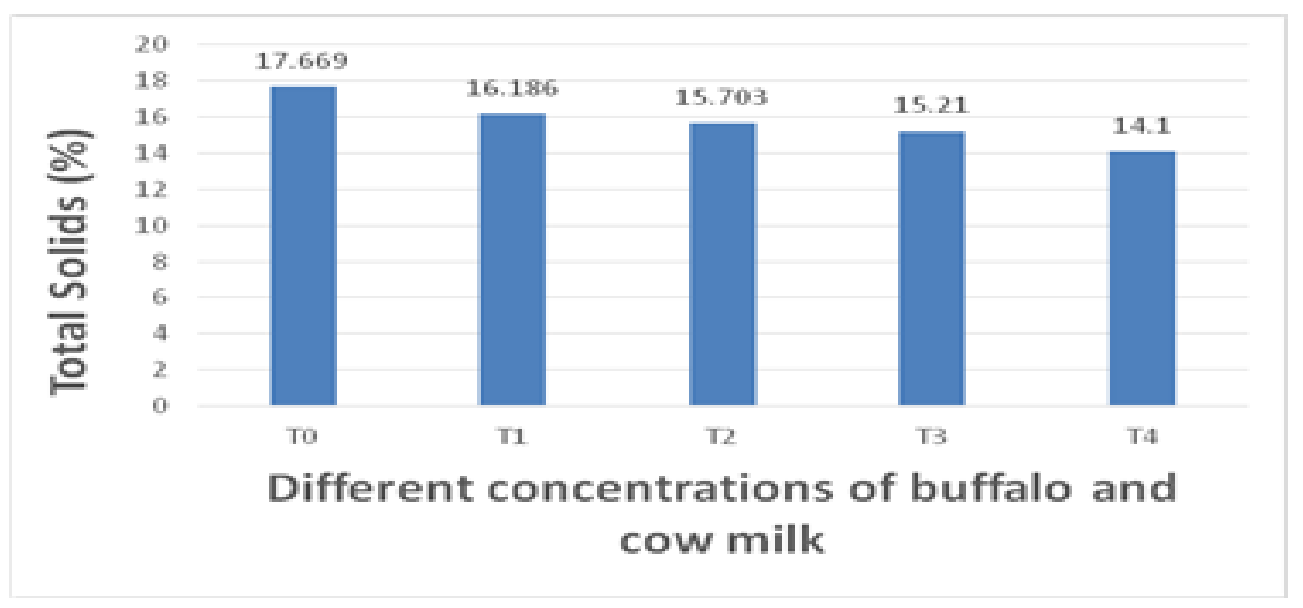

Whereas $\mathrm{T}_{0}=100 \%$ buffalo milk $+0 \%$ cow milk, $\mathrm{T} 1=75 \%$ buffalo milk $+25 \%$ cow milk blend, $\mathrm{T} 2=50 \%$ buffalo milk $+50 \%$ cow milk blend, $\mathrm{T} 3=25 \%$ buffalo milk $+75 \%$ cow milk blend, $\mathrm{T} 4=0 \%$ buffalo milk $+100 \%$ cow milk blend

\section{Figure 4. Mean values of total solid contents in the five groups of the flavored milk}

\section{Fat \%}

Fat content in the groups of flavored milks were higher in solely buffalo milk based flavored milks, as can be seen from the values and the heights of the bar chart (Fig. 5). 


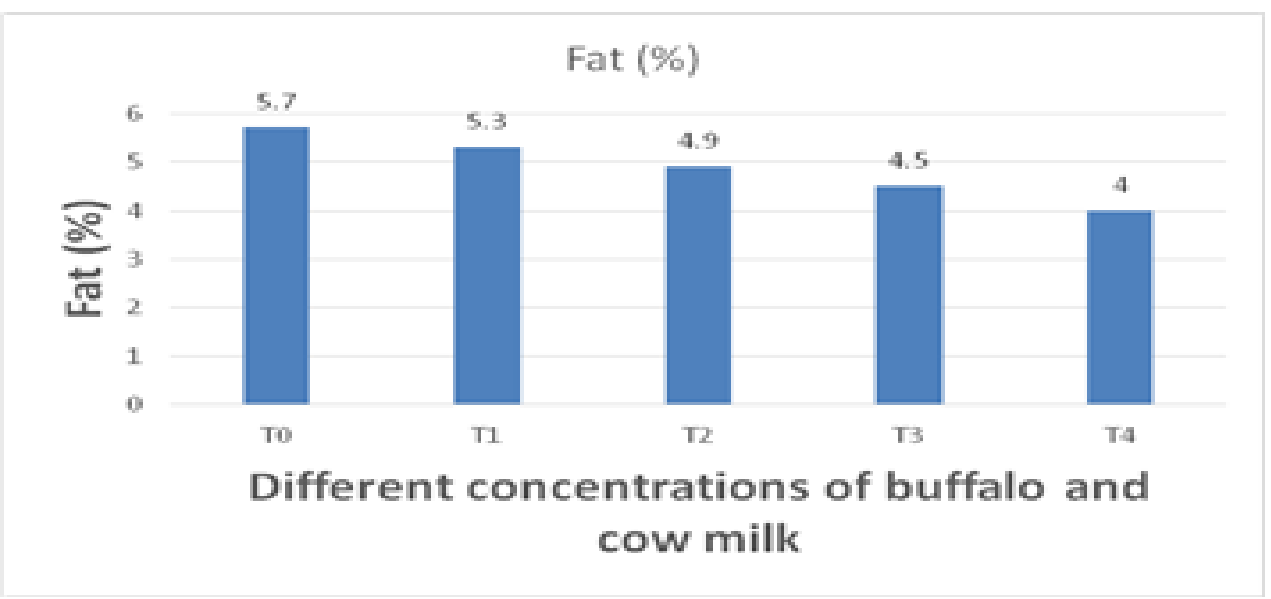

Whereas $\mathrm{T}_{0}=100 \%$ buffalo milk $+0 \%$ cow milk, $\mathrm{T} 1=75 \%$ buffalo milk $+25 \%$ cow milk blend, $\mathrm{T} 2=50 \%$ buffalo milk $+50 \%$ cow milk blend, $\mathrm{T} 3=25 \%$ buffalo milk $+75 \%$ cow milk blend, $\mathrm{T} 4=0 \%$ buffalo milk $+100 \%$ cow milk blend

Figure 5. Mean values of fat contents in the five groups of flavored milk

\section{SNF \%}

Like fats and total solids, SNF were also highest in flavored milks prepared solely from buffalo, and lowest in flavored milks prepared solely from cow milk, and the rest groups of flavored milk contains SNF within these extremes, and this trend was depicted from the bar chart in (Fig. 6). The difference in the level of SNF was also statistically significant $(\mathrm{p}<0.05)$ at $95 \%$ at confidence level.

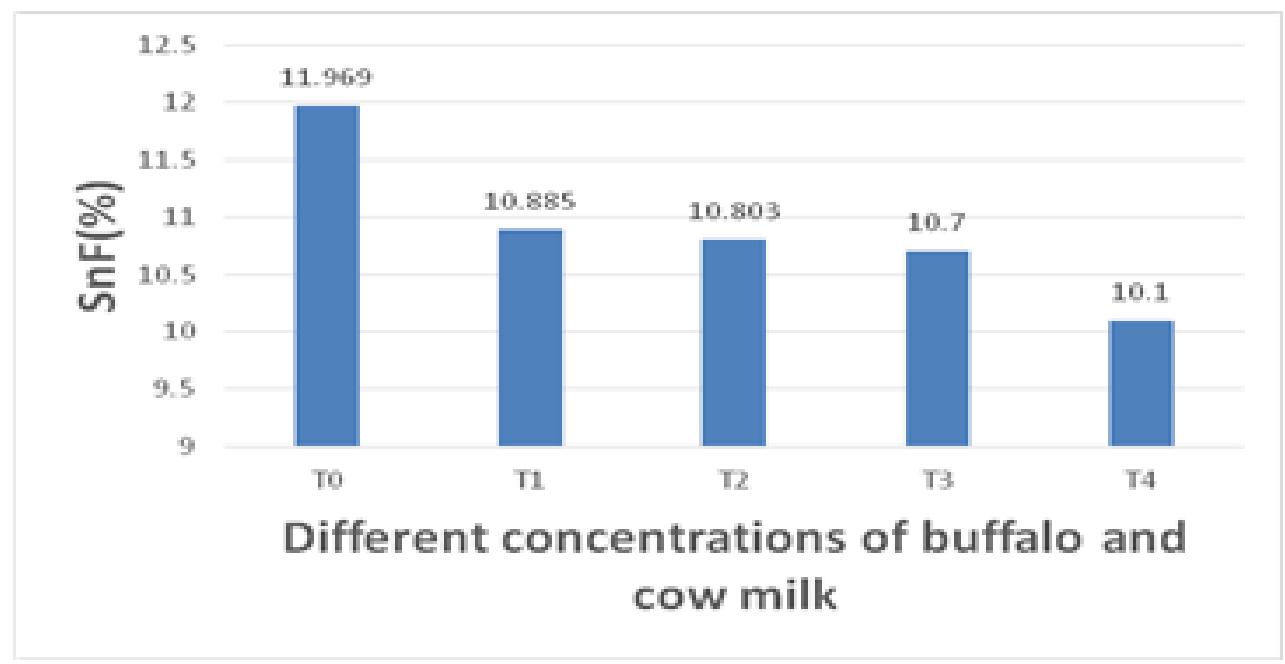

Whereas $\mathrm{T}_{0}=100 \%$ buffalo milk $+0 \%$ cow milk, $\mathrm{T} 1=75 \%$ buffalo milk $+25 \%$ cow milk blend, $\mathrm{T} 2=50 \%$ buffalo milk $+50 \%$ cow milk blend, $\mathrm{T} 3=25 \%$ buffalo milk $+75 \%$ cow milk blend, $\mathrm{T} 4=0 \%$ buffalo milk $+100 \%$ cow milk blend.

\section{Figure 6. Mean values of SNF in the five groups of flavored milk}

\section{Protein \%}

Flavored milk prepared from buffalo milk (T0) gave maximum protein contents on an average, flavored milks prepared from cow milk (T4) gave minimum; all other groups gave intermediate protein contents (Fig. 7); at $95 \%$ confidence level the difference was statistically significant $(\mathrm{p}<0.05)$. 


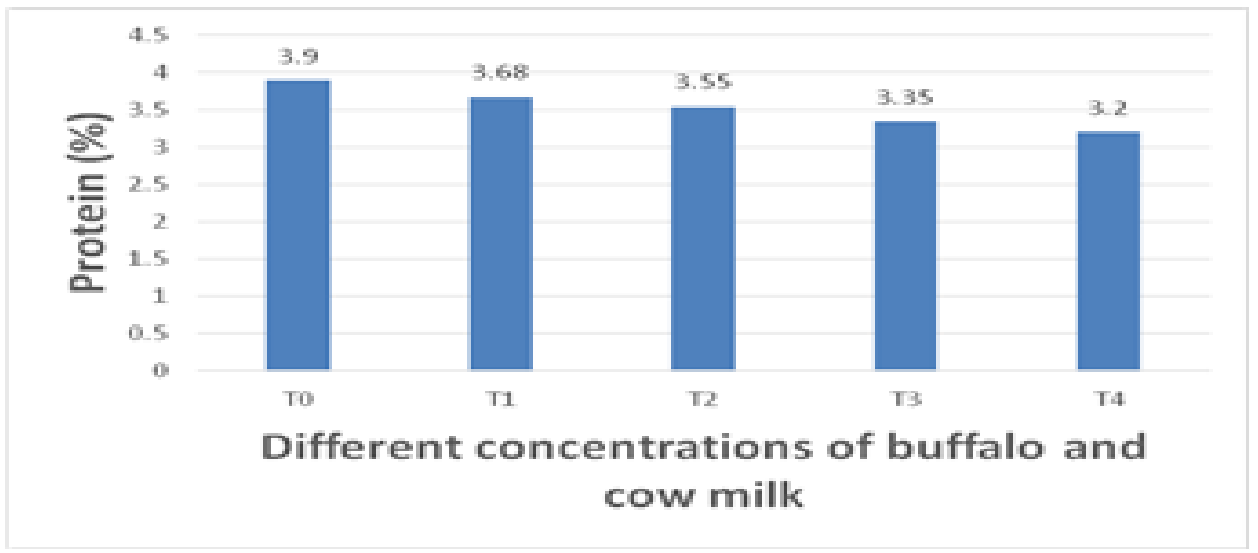

Whereas $\mathrm{T}_{0}=100 \%$ buffalo milk $+0 \%$ cow milk, $\mathrm{T} 1=75 \%$ buffalo milk $+25 \%$ cow milk blend, $\mathrm{T} 2=50 \%$ buffalo milk $+50 \%$ cow milk blend, $\mathrm{T} 3=25 \%$ buffalo milk $+75 \%$ cow milk blend, $\mathrm{T} 4=0 \%$ buffalo milk $+100 \%$ cow milk blend

\section{Figure 7. Mean values for protein contents in the five groups of flavored milks}

\section{Lactose \%}

Lactose is a disaccharide sugar found in milk, and is formed from molecules of galactose and glucose. It makes up only around $4.5 \sim 5 \%$ by weight of milk. But it is the milk constituent responsible for its sweetness, and the sole source of energy for new-born babies on mother's feed. It is water soluble, easily digestible, and is hence really beneficial for milk consumers. For diabetic patients however, lactose-free milk can also be processed. The flavored milk samples had significantly differed within the groups/treatments $\quad(\mathrm{p}<0.05) \quad$ at $95 \%$ confidence level (Fig. 8). It was found that the highest values in flavored milks having higher proportion of the buffalo milk than in the groups/treatments having higher proportion of cow milk. The highest values of lactose were found in purely buffalo based flavored milk, and the least in purely cow based flavored milk. The reason lies in source of milk itself.

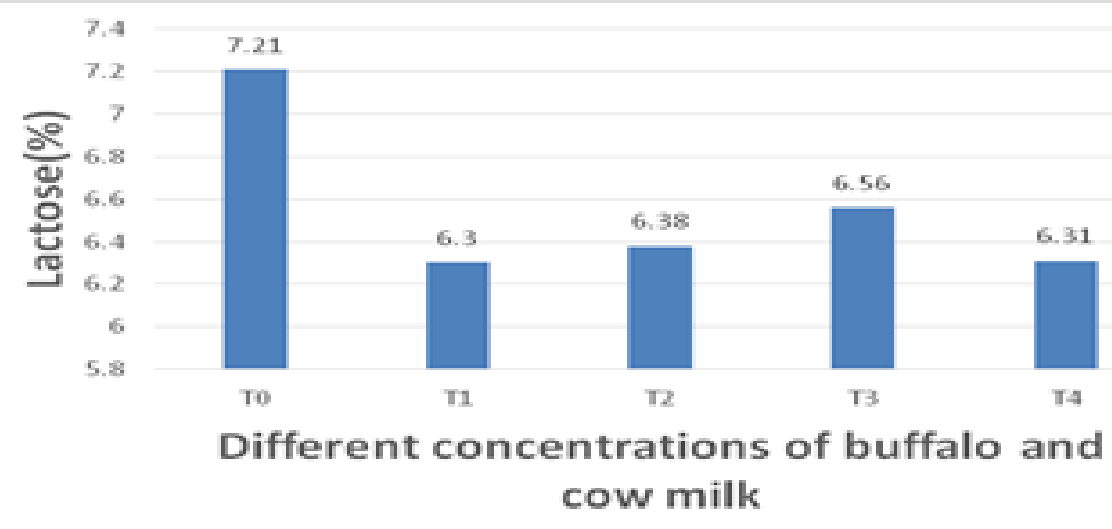

Whereas $\mathrm{T}_{0}=100 \%$ buffalo milk $+0 \%$ cow milk, $\mathrm{T} 1=75 \%$ buffalo milk $+25 \%$ cow milk blend, $\mathrm{T} 2=50 \%$ buffalo milk $+50 \%$ cow milk blend, $\mathrm{T} 3=25 \%$ buffalo milk $+75 \%$ cow milk blend, $\mathrm{T} 4=0 \%$ buffalo milk $+100 \%$ cow milk blend

Figure 8. Mean values of lactose content in the five groups of flavored milk 


\section{Ash\%}

The ash contents determined in this study are lying within or near the ranges defined by [13]; ash contents in buffalo based flavored milk being highest $(0.92 \%$ on average) and that in cow based flavored milk giving least ash content of $0.62 \%$ on average (Fig. 9).

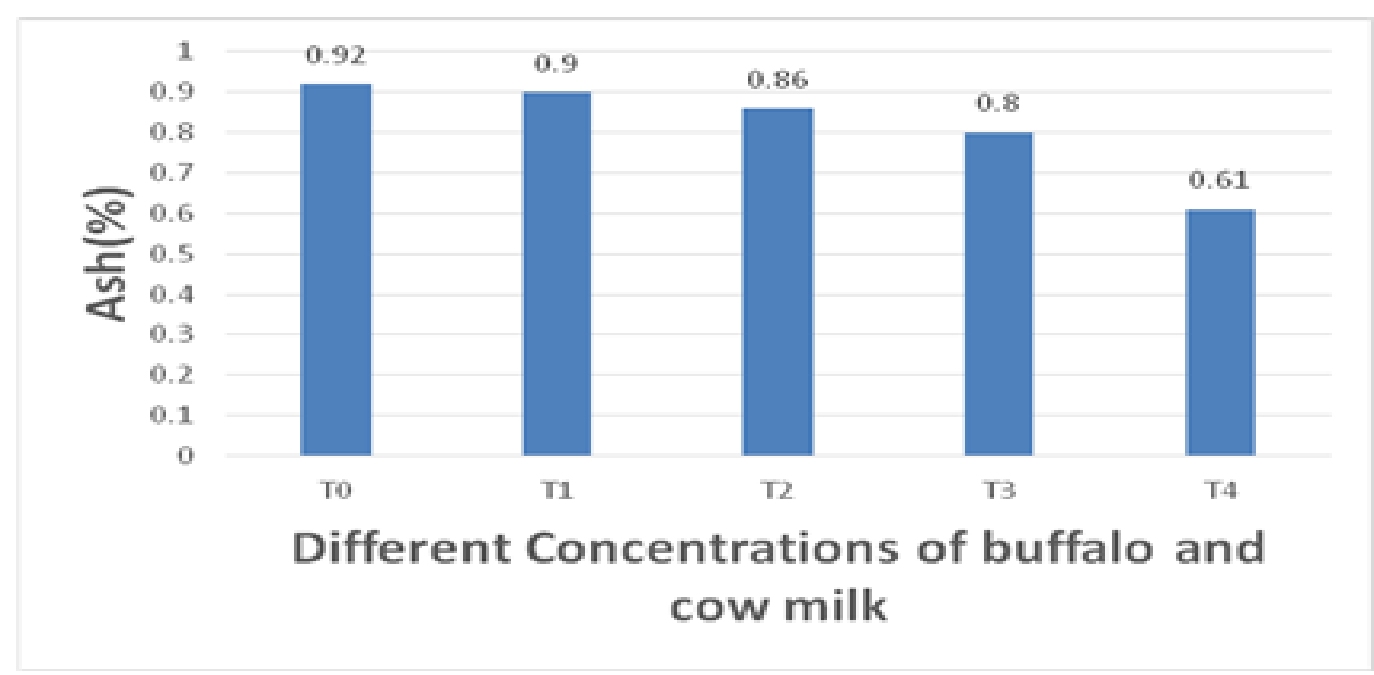

Whereas $\mathrm{T}_{0}=100 \%$ buffalo milk $+0 \%$ cow milk, $\mathrm{T} 1=75 \%$ buffalo milk $+25 \%$ cow milk blend, $\mathrm{T} 2=50 \%$ buffalo milk $+50 \%$ cow milk blend, $\mathrm{T} 3=25 \%$ buffalo milk $+75 \%$ cow milk blend, $\mathrm{T} 4=0 \%$ buffalo milk $+100 \%$ cow milk blend

Figure 9. Mean values of ash contents in the five groups of flavored milks

\section{Sensory evaluation}

The appearance, odour, flavour, colour, taste and overall acceptability of the flavored milks were defined by a group of trained judges (professional respondents), and their response was tabulated in crosstabs and the difference in their response was insignificant ( $>0.05$ ) as most or almost all of them voted for the buffalo milk based flavored milk (Table 2).

\section{Shelf life}

Shelf life is defined as the time for which milk quality remains clean and drinkable. After a certain period of refrigeration, microbial activity revives, and the putrefactive bacteria started growing and initiates milk decomposition or the degradation of milk constituents occur. Raw milk normally lasts drinkable for 2-3 days, but processes like pasteurization and addition of stabilizers and preservatives have marked effect on significant increase in shelf life of milks up to 7 days. Since pasteurization causes inactivation of bacteria while emulsifiers/stabilizers bound fats for long and control bacterial action on it.

Overall acceptability of the milk was defined by professional respondents, and their response was tabulated in crosstabs and the difference in their response was insignificant ( $p>0.05)$ as most or almost all of them voted for the buffalo milk based flavored milk (Table 2).

\section{Discussion}

Pakistan is famous for producing traditional food items and a number of conventional and modern as well as packaged and open sold dairy products such as rabri, falooda, kheer, firni, lassi, etc. Quality of such products has however scarcely come under investigations. 
Table 2. Tabulation of responses for sensory evaluation of milk samples

\begin{tabular}{|c|c|c|c|c|c|c|}
\hline & 1 & 2 & 3 & 4 & 5 & All \\
\hline \multirow{4}{*}{1} & 6 & 5 & 4 & 3 & 2 & 20 \\
\hline & 30.00 & 25.00 & 20.00 & 15.00 & 10.00 & 100.00 \\
\hline & 12.00 & 10.00 & 7.69 & 6.00 & 4.00 & 7.94 \\
\hline & 2.381 & 1.984 & 1.587 & 1.190 & 0.794 & 7.937 \\
\hline \multirow{4}{*}{2} & 12 & 15 & 12 & 9 & 8 & 56 \\
\hline & 21.43 & 26.79 & 21.43 & 16.07 & 14.29 & 100.00 \\
\hline & 24.00 & 30.00 & 23.08 & 18.00 & 16.00 & 22.22 \\
\hline & 4.762 & 5.952 & 4.762 & 3.571 & 3.175 & 22.222 \\
\hline \multirow{4}{*}{3} & 24 & 20 & 28 & 27 & 16 & 115 \\
\hline & 20.87 & 17.39 & 24.35 & 23.48 & 13.91 & 100.00 \\
\hline & 48.00 & 40.00 & 53.85 & 54.00 & 32.00 & 45.63 \\
\hline & 9.524 & 7.937 & 11.111 & 10.714 & 6.349 & 45.635 \\
\hline \multirow{4}{*}{4} & 4 & 5 & 4 & 6 & 15 & 34 \\
\hline & 11.76 & 14.71 & 11.76 & 17.65 & 44.12 & 100.00 \\
\hline & 8.00 & 10.00 & 7.69 & 12.00 & 30.00 & 13.49 \\
\hline & 1.587 & 1.984 & 1.587 & 2.381 & 5.952 & 13.492 \\
\hline \multirow{4}{*}{5} & 3 & 3 & 4 & 3 & 5 & 18 \\
\hline & 16.67 & 16.67 & 22.22 & 16.67 & 27.78 & 100.00 \\
\hline & 6.00 & 6.00 & 7.69 & 6.00 & 10.00 & 7.14 \\
\hline & 1.190 & 1.190 & 1.587 & 1.190 & 1.984 & 7.143 \\
\hline \multirow{4}{*}{6} & 1 & 2 & 0 & 1 & 3 & 7 \\
\hline & 14.29 & 28.57 & 0.00 & 14.29 & 42.86 & 100.00 \\
\hline & 2.00 & 4.00 & 0.00 & 2.00 & 6.00 & 2.78 \\
\hline & 0.397 & 0.794 & 0.000 & 0.397 & 1.190 & 2.778 \\
\hline \multirow{4}{*}{7} & 0 & 0 & 0 & 1 & 1 & 2 \\
\hline & 0.00 & 0.00 & 0.00 & 50.00 & 50.00 & 100.00 \\
\hline & 0.00 & 0.00 & 0.00 & 2.00 & 2.00 & 0.79 \\
\hline & 0.000 & 0.000 & 0.000 & 0.397 & 0.397 & 0.794 \\
\hline \multirow{4}{*}{8} & 0 & 0 & 0 & 0 & 0 & 0 \\
\hline & $*$ & $*$ & $*$ & $*$ & $*$ & $*$ \\
\hline & 0.00 & 0.00 & 0.00 & 0.00 & 0.00 & 0.00 \\
\hline & 0.000 & 0.000 & 0.000 & 0.000 & 0.000 & 0.000 \\
\hline \multirow{4}{*}{9} & 0 & 0 & 0 & 0 & 0 & 0 \\
\hline & $*$ & $*$ & $*$ & $*$ & $*$ & $*$ \\
\hline & 0.00 & 0.00 & 0.00 & 0.00 & 0.00 & 0.00 \\
\hline & 0.000 & 0.000 & 0.000 & 0.000 & 0.000 & 0.000 \\
\hline \multirow{4}{*}{ All } & 50 & 50 & 52 & 50 & 50 & 252 \\
\hline & 19.84 & 19.84 & 20.63 & 19.84 & 19.84 & 100.00 \\
\hline & 100.00 & 100.00 & 100.00 & 100.00 & 100.00 & 100.00 \\
\hline & 19.841 & 19.841 & 20.635 & 19.841 & 19.841 & 100.000 \\
\hline
\end{tabular}

Using frequencies in Frequency

Rows: Taste $(1=$ Extremely like, 2 = like very much, $3=$ like moderately, $4=$ like slightly, $5=$ neither like nor dislike, 6 = dislike slightly, $7=$ dislike moderately, $8=$ dislike very much, $9=$ dislike extremely)

Columns: Group $(1=100 \%$ buffalo, $2=75 \%$ buffalo $+25 \%$ cow, $3=50 \%$ buffalo $+50 \%$ cow, $25 \%$ buffalo $+75 \%$ cow, $5=100 \%$ cow)

Cell Contents: Count

$\%$ of Row

$\%$ of Column

$\%$ of Total

Pearson Chi-Square $=29.983, \mathrm{p}$-value $=1.000$

Likelihood Ratio Chi-Square $=29.637$, p-value $=1.000$ 
This study was carried out to assess the quality of flavored milks produced from Nili Ravi buffalo and Holstein Friesian cow milk and their 3:1, 1:1 and 1:3 blends in terms of its composition, or all the essential and nonessential constituents such as lactose, fat, solid-not-fat, protein, total solids, ash; as well as the physico-chemical properties that are indirect means of quality assessment and spoilage checks like $\mathrm{pH}$, titrable acidity and specific gravity.

Titrable acidity is the amount of acid present in a solution. It is assessed as an indirect measure of its shelf life in context of its thermal stability. Milk contains phosphates, citrates, hydrogen ions and dissolved carbon dioxide that naturally give acidity to it, which is added up by the presence of lactic acid produced by the action of bacteria on lactose in the milk [1]. The contrary relation of $\mathrm{pH}$ and acidity was also explained by [14, 15] who elaborated that lower $\mathrm{pH}$ means a high acidity or a high acidic strength though the concentration of acid may be low. These values and the level of significance of difference in $\mathrm{pH}$ in the five groups are in agreement with the $\mathrm{pH}$ values of the sources from where the flavored milks were prepared; i.e. the fresh cow and buffalo milk, as obtained by $[6,16,17]$ who analyzed $\mathrm{pH}$ of fresh cow and buffalo milk separately and that of [15] who made comparison of various species of milk producing animals. Slightly high $\mathrm{pH}$ was observed in cow milk based flavored milks (Fig. 2).

The results of specific gravity are not in agreement with the findings of [13] except for the level of significance of the difference between the specific gravity of fresh buffalo and cow milk $(\mathrm{p}<0.05$ in our case and $\mathrm{p}<0.01$ as determined by [13]; but in accordance with the results of [18] due to reasons like the lactation phase/period of the animal, time of milking or the amount of milk it has produced before the sample milking and the diet of the animal; all of which directly affected the milk composition.

Total solids results are in agreement with the findings of $[16,19,20]$ though they worked on raw buffalo milk, with $[6,17,21]$ who worked on raw cow milk total solid contents, and with [13] who compared buffalo, cow, goat and sheep milk quality. The results of comparison are statistically significant $(\mathrm{p}<0.05)$ while the results of [13] were highly significant $(\mathrm{p}<0.001)$. The main reason is that genetically water content is lower in buffalo and higher in cow milk, whereas fat, SNF and protein are higher in buffalo and lower in cow milk [18].

Similarly fat \%age results are also in agreement with the findings of [18] who compared cow and buffalo milk at different stages of lactation after feeding them on grazing systems designed specifically for them, deducing buffalo milk protein content double as that of the cow milk protein content, and found it to rely on the period of milking and the time after milking; as well as on provided diet (naturally) and on genetic makeup of the species. The values for SNF are in agreement with the ranges reviewed by [22] that attributed the wide variation in milk composition (SNF contents) to genetic makeup of the animal, its physiology, diet, and lactation period as well as the environmental factors. Values however exceeded those defined by [13] possibly due to the addition of sugar and flavor for the preparation of the flavored milks.

Parallel comparison was observed in present results and by [13]. They measured the statistical significance of difference in protein contents of the milk of various milk producing species $(\mathrm{p}<0.001)$; protein content in sheep to vary between 5.01 and $5.59 \%$, than buffalo to vary between 4.13 and $4.59 \%$, that of cow to vary between 3.05 and $3.69 \%$, and that of goat to vary between 2.87 
and $2.47 \%$; with closeness to our estimations for buffalo and cow milk samples. [6] assessed the quality of cow and buffalo milk and the items processed from these milk sources, and gave protein contents of buffalo lower than our estimation $(3.6<3.9)$ and that of cow milk protein content same as estimated in this study $(3.2=3.2)$.

Mahmood and Usman [13] found more lactose in buffalo milk in comparing buffalo, cow and goat milk samples with statistical significance $(p<0.001)$ at $99.9 \%$ level of confidence. The values were, however, higher than those reported by [13] possibly because the animals may have been fed with high fiber diet which increases lactose in milk [23]. Ash is produced from milk due to the nutrients such as sodium, potassium, calcium, magnesium, etc. As determined by [13] for raw milk ash contents from all the milk producing species; ash contents in the buffalo based flavored milk is maximum $(0.81 \%$ with a standard deviation of $0.09 \%)$, and in cow based milk it is minimum $(0.6 \%$ with a standard deviation of $0.13 \%$ ), with high statistical significance $(\mathrm{p}<0.001)$. Similarly [6] also determined the range for ash content in cow and buffalo milk and some of the items processed from these milk sources, giving ash contents of cow milk near to our estimation as $0.65 \%$ and that for buffalo as $0.76 \%$ which was lower as compared to our estimation. Ash content estimated by [19] for buffalo milk from China averaged on 112 milk samples $(0.85 \%)$ is however, somewhat closer to our buffalo milk ash content.

Another aim of the present study was to evaluate which of buffalo and cow milk or their blends will best meet consumers demand in terms of its compositional quality and taste.

\section{Conclusion}

It was concluded from the present study that the milk quality is significantly affected by alteration of its sources/constituents. Flavored milk prepared from sole buffalo and cow milks carry extreme values for all the tested quality parameters. Flavored milk produced from buffalo milk (100\%) was best among all the five groups of flavored milks with respect to quality parameters (chemical constituents: total solids, fat, SNF, protein and lactose (high); ash (low) as well as physical parameters such as $\mathrm{pH}$ (low), titrable acidity (high) and specific gravity (high). Shelf life of all the flavored milk groups was however 7 days. It is recommended in the light of present research findings that flavored milk must be produced from buffalo milk for Pakistani markets, as Pakistani consumers always prefer buffalo milk over cow milk for its taste, odor and color. Moreover, it is also rich in all the required constituents and will be beneficial for school going children.

\section{Authors' contributions}

Conceived and designed the experiments: S Inayat, Performed the experiments: A Nazir, Analyzed the data: $\mathrm{T}$ Tunio, Contributed reagents/ materials/ analysis tools: $\mathrm{MH}$ Lashari, Wrote the paper: S Inayat.

\section{References}

1. Bylund G (1995). Dairy processing handbook. Tetra Pak Processing Systems AB S-221 86 Lund (Sweden). pp. 436.

2. Economic Survey of Pakistan (2018-19). GOP. Government of Pakistan, Economic Advisor's Wing, Finance Division, Islamabad (Pakistan).

3. Ahmad S, Anjum FM, Huma N, Sameen A \& Zahoor T (2013). Composition and physico-chemical characteristics of buffalo milk with particular emphasis on lipids, proteins, minerals, enzymes and Vitamins. J Anim and Plant Sci 23(1 Suppl): 62-74.

4. Navale D \& Gupta S (2016). Comparative Study of Buffalo Milk and Cow Milk Samples Containing Reducing Sugar and Solid Not Fat. IJLTEMAS 5(5): 36-40

5. Salman M, Khaskheli MA, Israr-ul-Haq, Talpur AR, Khuhro AP, Rauf M, Hamid H \& Aziz A (2014). Comparative studies on nutritive quality of buffalo and cow 
milk. Int J Res Appl, Nat and Social Sci 12(2): 69-78.

6. Enb A, Abou Donia MA, Abd-Rabou NS, Abou- Arab AAK \& El-Senaity MH (2009). Chemical composition of raw milk and heavy metals behavior during processing of milk products. Global Vet 3: 268-275.

7. Johnson RK, Frary C \& Wang MQ (2002). The nutritional consequences of flavored milk consumption by schoolaged children and adolescents in the United States. J Am Diet Assoc 102: 853856.

8. Pelsmaeker DeS, Schouteten J \& Gellynck X (2013). The consumption of flavored milk among a children population. The influence of beliefs and the association of brands with emotions. Appet, 71: 279-286.

9. AOAC (2012). Official methods of the Association of Official Analytical Chemists. Washington, DC.

10. Marshall RJ (1993). Physicochemical properties accounting for cheese texture. Acta Psychol 84: 69-77.

11. O’Mohaney F (1988). Rural Dairy Technology- Experiences in Ethiopia. ILCA manual No. 4. Dairy Technology Unit. ILCA, Addis Abeba (Ethopia). pp. 64.

12. Richardson HG (1985). Standards methods for the examination of Dairy products. 6th edn. American Public Health Association, Washington DC. pp. 133-150.

13. Mahmood A \& Usman S (2010). A Comparative Study on the Physicochemical Parameters of Milk Samples Collected from Water buffalo, Cow, Goat and Sheep of Gujrat, Pakistan. Pak J Nutr 9(12): 1192-1197.

14. Tomovska J, Gjorgievski N \& Makarijoski B (2016). Examination of $\mathrm{pH}$, Titratable Acidity and Antioxidant
Activity in Fermented Milk. $J$ Materials Sci and Eng A 6(11-12): 326-333.

15. Kanwal R, Ahmed T \& Mirza B (2004). Comparative analysis of quality of milk collected from buffalo, cow, goat and sheep of Rawalpindi/Islamabad region in Pakistan. Asian Plant Sci 3: 300-305.

16. Braun PG \& Stefanie PE (2008). Nutritional composition and chemicophysical parameters of water buffalo milk and milk products in Germany. Milchwiss. Milk Sci Int 63: 70-72.

17. Imran M, Khan H, Hassan SS \& Khan R (2008). Physicochemical characteristics of various milk samples available in Pakistan. J Zhejiang Univ Sci B 9: 546551.

18. Fundora GO, Lezcano ME, Montejo O, Pompa A \& Enriquez N (2001). A comparative study of milk composition and stability of Murrah river buffaloes and Holstein cows grazing star grass. Cuba. J Agric Sci 35: 219-222.

19. Bei-Zhong H, Meng Y, Min L, Yang YX, Ren ZF, Zeng QKQ \& Nout VR (2007). A survey on the microbiological and chemical composition of buffalo milk in China. Food Control 18: 742-746.

20. Zaman G, Goswami RN \& Aziz A (2007). Milk constituents of swamp buffalo of Assam. Buffalo Bull 26: 25-28.

21. Mahboba IAA \& El-Zubeir IEM (2007). The compositional quality of raw milk produced by some dairy cow's farms in khartoum state, Sudan. Res. J Agric Biol Sci 3: 902-906.

22. Walsh J (1977). Factors affecting the solids-not-fat content of the milk of herds. Inter J Dairy Tech 21(2): 62-71.

23. Rubporn K, Sanguandeekul R, Sakulbumrungsil R \& Phongphanphanee $P$ (2007). Factors affecting lactose quantity in raw milk. J Sci 29(4): 937943. 